\title{
Ständige Abkürzungen
}

\section{Zeitsehriften}

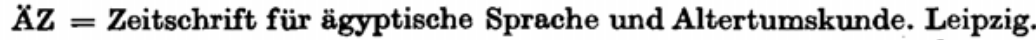
Annal. du Serv. = Annales du Service des Antiquités de l'Egypte. Cairo.

AO $=$ Der alte Orient. Leipzig.

Bull. inst. fr. = Bulletin de l'institut français d'archéologie orientale. Le Caire.

DLZ = Deutsche Literaturzeitung. Berlin.

GGA = Göttingische gelehrte Anzeigen.

JEA $=$ Journal of Egyptian Archaeology. London.

MVAeG = Mitteilungen der Vorderasiatischen (Vorderasiatisch-Aegyptischen) Gesellschaft. Leipzig.

$\mathrm{OLZ}=$ Orientalistische Literaturzeitung. Leipzig.

PSBA = Proceedings of the Society of Biblical Archaeology. London.

Rec. de trav. = Recueil de travaux relatifs à la philologie et à l'arch́́o. logie égyptiennes et assyriennes. Paris.

\section{Einzelne Werke}

Äg. Wb. = A. Erman u. H. Grapow, Wörterbuch der ägyptischen Sprache I-V. Leipzig 1926/31.

v. Bissing-Kees, Re-Heiligtum = Das Re-Heiligtum des Ne-WoserRe (Rathures) hreg. von Fr. W. Frh. v. Bissing II-III. Leipzig 1923/28.

Bonnet, Bilderatlas $=$ Bilderatlas zur Religionsgeschichte, hrsg. von H. Hass. 2.-4. Lief.: Ägyptische Religion. Leipzig 1924.

Borchardt, Neuserrê; Sahurê = Das Grabdenkmal des Königs Neuser-Re' bzw. S'a'hụ -Re'. Wiss. Veröffentl. der Deutschen Orient-Ges. Bd. 7 (1907), 14 (1910), 26 (1913).

Brugsch, Thesaurus = Thesaurus inscriptionum aegyptiacarum. Leipzig 1883/91.

de Buck, Coffintexts = The Egyptian Coffintexts. Oriental Institute (Chicago) Publications. Bd. 34. 49. Chicago 1934. 1938.

Edfou $=$ de Rochemonteix-Chassinat, Le temple d'Edfou I-XIV. Mómoires publiés par les membres de la Mission archéologique française au Caire. Le Caire 1892/1934.

Hopfner, Tierkult $=$ Der Tierkult der alten Ägypter. Denkschr. Wiener Akad. phil.-hist. Klasse Bd. 57, 2 (1913).

Junker, Onurislegende $=$ Die Onurislegende. Denkschr. Wiener Akad. phil.-hist. Klasse Bd. 59, 1-2 (1917). 
Kees, Kulturgeschichte $=$ Handbuch der Altertumskunde. Kultur . geschichte des Alten Orients III. Abt. 1. Abschnitt: Ägypten. München 1933.

Kees, Lesebuch $=$ Religionsgeschichtliches Lesebuch. 2. Aufl. hrsg. von A. Bertholet. Heft 10: Ägypten. Tübingen 1928.

Kees, Totenglauben $=$ Totenglauben und Jenseitsvorstellungen der alten Ägypter. Leipzig 1926.

Klebs, Reliefs AR(MR, NR) = Die Reliefs des Alten Reiches. Die Reliefs und Malereien des Mittleren Reiches. Die Reliefs und Malereien des Neuen Reiches I. Abh. Heidelberger Akademie. 1915. 1922. 1934.

Lacau TR = Lacau, Textes religieux Nr. $1-90$ in Rec. de trav. Bd. 26-37. Paris.

LD $=$ R. Lepsius, Denkmäler aus Ägypten u. Äthiopien. Abt. I-VI. Berlin 1849f. Textbände I-V. Leipzig $1897 \mathrm{f}$.

Ombos = Catalogue des monuments et inscriptions de l'Égypte antique. J. de Morgan pp., Kom Ombos I-II. Wien $1895 \mathrm{f}$.

E. Otto, Stierkulte $=$ Beiträge zur Geschichte der Stierkulte in Agypten. Untersuchungen zur Geschichte und Altertumskunde Ägyptens Bd. 13. Leipzig 1938.

Pauly $\cdot$ Wissowa RE = Realenzyklopädie der klassischen Altertumswissenschaft 2. Aufl. Stuttgart.

Pyr. = Sethe, Die altägyptischen Pyramidentexte. Leipzig $1908 \mathrm{f}$.

Pyr. Kommentar $=$ Sethe, Ubersetzung und Kommentar zu den altägyptischen Pyramidentexten I-IV. Glückstadt o. J.

Schäfer-Andrae, Propyläen-Kunstgeschichte II = H. Schäfer u. W. Andrae, Die Kunst des Alten Orients. Berlin (1. Aufl. 1925. 2. Aufl. 1930).

Sethe, Amun = Amun und die acht Urgötter von Hermopolis. Abh. Berl. Akad. 1929.

Sethe, Dramatische Texte $=$ Dramatische Texte zu altägyptischen Mysterienspielen. Untersuchungen zur Geschichte und Altertums. kunde Ägyptens. Bd. 10. Leipzig. 1928.

Sethe, Urgeschichte = Urgeschichte und älteste Religion der Ägypter. Beiheft zur Zeitschrift der Deutschen Morgenländischen Gesellschaft. Leipzig 1930.

Tb. (Kap.) = Totenbuch. Kapitel nach der Ausgabe von Naville, Das ägyptische Totenbuch der XVIII.-XX. Dynastie. Leipzig 1886.

Urk. = Urkunden des ägyptischen Altertums hrsg. von G. Stein dorff. Abt. I-VII. Leipzig. 